\title{
Evaluation of the modified braille dots printed with the UV ink-jet technique
}

\begin{abstract}
Braille presents a complex system of writing with additional symbols and letters designating numbers, capital letters and other special symbols in mathematics, physics, music etc. Due to mentioned braille texts are usually very long, bulky, space consuming and complex. In this research a study of modified braille dots is presented. Samples were prepared in several different steps, enabling the determination of the optimal braille dot height on top which additional elements were printed. Properties of ordinary braille dot samples and braille dot samples printed with additional element were compared and analyzed. An extensive sensory analysis with blind and visually impaired people was performed for establishing weather modified braille dots can be tactile recognized and used in practice.
\end{abstract}

\section{KEY WORDS}

braille dots, UV ink-jet, modified braille dots, blind and visually impaired

\author{
Raša Urbas ${ }^{1}$, \\ Bojan Rotar ${ }^{1}$, \\ Peter Hajdu², \\ Urška Stankovič Elesini ${ }^{1}$ \\ ${ }^{1}$ University of Ljubljana, Faculty of \\ Natural Sciences and Engineering, \\ Ljubljana, Slovenia \\ ${ }^{2}$ Grec grafično tehnološki center \\ d.o.o., Ljubljana, Slovenia
}

Corresponding author: Raša Urbas e-mail: rasa.urbas@ntf.uni-lj.si

First recieved: 05.08.2016. Accepted: 29.08.2016.

\section{Introduction}

In the past Braille has mainly been printed by embossing or screen printing while in the last decade newer technologies like UV ink-jet and 3D printing are taking their place. Printing braille is no longer limited only to the paper or the cardboard but nowadays, prints can be made on almost any printing material (foil, glass, plastic, wood, textiles etc.). New technologies enable precise printing of elements not only in $2 \mathrm{D}$ but also in $3 \mathrm{D}$, where later plays an important role the braille field, due to the fact that braille needs to be tactile recognizable.

Braille consists of braille cell, which comprises of six dots, arranged in two columns of three dots. The size and the height of each braille dot, as well as all the other ratios between the individual dots and cells are determined according to the different standards, regulations and recommendations (European Commission: Enterprise and Industry Directorate-General, 2001; Österreichisches Normungsinstitut für Normung e.V., 2006; Deutsches
Institut für Normung e.V., 2007; Deutsches Institut für Normung e.V., 2009; International Standardization Organization, 2013a; International Standardization Organization, 2013b; International Standardization Organization, 2014), although those requirements can slightly differ. According to the selected standards/regulations, required parameters of braille dot and cell are: the specific values of the dot height $0.25-1.0 \mathrm{~mm}$, diameter of the dot 1.0-1.8 mm, distance between centers of two horizontally or vertically set dots in the cell $2.0-3.0 \mathrm{~mm}$, distance between the center of the first braille dot in one and the next adjacent braille cell in the next row 5.0-9.78 $\mathrm{mm}$ and the distance between the center of first braille dot in one and next adjacent braille cell in the same row 8.46-17.2 mm (Deutsches Institut für Normung e.V., 2007; European Committee for Standardization, 2008; Fajdetić, 2012; International Standardization Organization, 2013a; International Standardization Organization, 2013b).

Preparation of different printed material, intended for communication, education and inclusion of blind and 
visually impaired people is complex. Braille alphabet has (regardless of the language) additional characters for indicating for example capital letters, numbers or any other special symbols. Designation of separate elements and formulas in mathematics, chemistry and physics (American association of workers for the blind, Association for education of the visually handicapped and the National braille association, 1987; La Commission Évolution du Braille Français, 2007) or for example music notation (Braille authority of North America, 1997; Hee, 2015) is very complex and time consuming work. Due to additional braille symbols/characters and prescribed braille cell dimensions, the notations in braille are usually much longer as the notations in Latin thus, takes more (physical) space, are bulky and connected with the higher costs for printing.

The technology of UV ink-jet printing enables precise printing even of the smallest elements, which can be printed in one or more layers. The thickness of the prints e.g. printing layers is however, limited by the distance (height) between the printing substrate and the printing head with nozzles (Reynaud, 1995; Zhang, 2011; Chang, 2012; Shi-Chang \& Rui-Zhang, 2013; Soleimani-Gorgani, 2016). The technique enables the use of UV printing inks or varnishes in selected printer's color gamut of any combination. UV light causes in the process of drying the polymerization of printed layer/s of the UV ink or the varnish, by which the printed surface become solid. Dried and polymerized printed layers enable the production of smooth surface of the printed elements. Thanks to the possibilities of printing in different layers and in different sizes (large and detailed), by this techniques various shapes of 3D tactile elements can be produced.

In this research, braille dots were printed with different number of layers (from one to five) on the higher grammage cardboard substrate with the selected ink-jet printer and UV varnish. Further, after the characteristics and the properties of the printed samples were determined, and when the desired height of prints was achieved, $(0.25-1.0 \mathrm{~mm}$, as recommended), the additional element with different number of layers (also from one to five) was printed on the braille dots (Figure 1). All the samples were measured and analyzed and their results were compared. a)

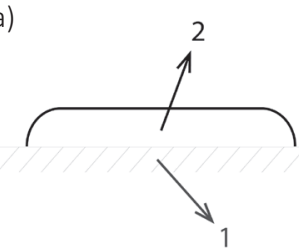

b)

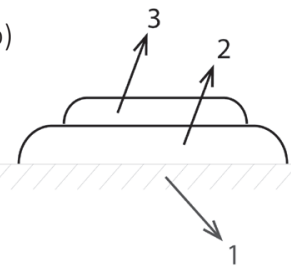

„ Figure 1: The braille dot (a) and the braille dot with the additional element (b) (1-printing material; 2 - braille dot; 3 -additional printed element on braille dot)
Since blind and visually impaired people feel and recognize differently structured surfaces, the aim of the research was to establish whether elements on the braille dot are recognized and also distinguished by blind and visually impaired people and whether the height of the modified braille dot (with additional element) can be distinguished according to the height of the braille dot. For this purpose, samples were analyzed by the methods described in continuation, however a sensory analysis was also performed by the blind and visually impaired people.

The main idea of the additional elements, printed on the braille dot, was to simplify the complex notations in braille. Instead of standard braille characters for indicating capital letters, math, music, chemistry or any other notations for equations, formulas, notes, etc., the simple dot with added element or just different height would be used. Such simplification would enable easier, faster, more effective and above all shorter, less bulky and space consuming prints in braille.

\section{Materials}

\section{Printing substrate}

In the research cardboard Krompak ${ }^{\mathrm{TM}}$ (Količevo Karton d.o.o., 2005) was used as a printing substrate. According to the manufacturer's technical specification, the cardboard was composed mainly of $60 \pm 10 \%$ virgin cellulose fibers, to which $30 \pm 15 \%$ of "postindustrial" waste material (wood free, unprinted, white paper only) and $10 \pm 5 \%$ of the coating was added; it had a smooth surface and correspondingly good adhesion between the printing ink/varnish and the printing surface. The other declared technical characteristics of the printing substrate Krompak ${ }^{\mathrm{TM}}$ were: grammage $250 \mathrm{~g} / \mathrm{m}^{2}$, thickness $395 \mu \mathrm{m}$, volume - bulkiness 1.61 $\mathrm{cm}^{3} / \mathrm{g}$ and bending stiffness at $15^{\circ}$ bend: $\mathrm{MD}-14.0$ $\mathrm{mNm}, \mathrm{CD}-6.2 \mathrm{mNm}$; L\&W stiffness $16.9 \mathrm{mNm}$.

\section{Printing technique and printing ink}

Prints were made on the UV ink-jet printer DG LEC-330 (Roland DG Corporation, Japan). The piezo electric printer enables precise and thick prints of tactile elements and braille dots by printing several layers of printing ink or varnish separately one on the top of another. All layers need to be printed in high quality, so that the shape and the thickness of the prints are maintained through the process of layer printing. For that purpose, printing in high resolution $1440 \mathrm{dpi}$ is critical for achieving high accuracy of prints, despite its slowness. Depending on the thickness of the printing substrate maximum height of prints $1.5 \mathrm{~mm}$ can be achieved (Roland, 2016). In our research prints were made with ECO - UV Gloss 
(clear gloss) printing varnish (Roland DG Corporation, Japan). Printing varnish had (according to the manufacturers specification) low viscosity, high gloss, good adhesion to different materials, either on coated or uncoated materials (including foils, paper, films and vinyl), good cracking, scratch and chemical resistance and outdoor durability (Wensco, 2016). Unfortunately, the numerical values were not available by the producer. Each layer was dried before printing of another layer, thus maintaining desired diameter of the printed element and providing printing without bleeding.

\section{Sample preparation and designation}

The samples were prepared through the following steps: 1) preliminary printing of the braille dots on the cardboard without and with a thin layer of the UV varnish (same as it was used for printing braille dots); 2) obtained samples were tested and the most appropriate was chosen for the continuation of the research (the testing and the obtained results are presented in the section "Properties of the substrates (samples S1 and S2)"); 3) braille dots in layers (from one to five) were printed on the suitably prepared surface of the cardboard; 4) samples were tested and among them, the one with the optimal number of the printing layers according to the standard requirements was chosen for the continuation of the research; 5) smaller elements in the shape of a circle were printed on the braille dots in different layers (from one to five) (although the additional elements printed on the braille dots were of different shapes (circle, square, triangle, etc.), for the purpose of this paper, only braille dots with circle element were chosen and results are represented).

For easier understanding, the samples were designated as follows:

- $\mathrm{S}_{1}=$ unprinted cardboard;

- $\mathrm{S}_{1 \mathrm{~B}}=\mathrm{S}_{1}+$ braille dots printed with the UV varnish in different layers (from one to five);

- $\mathrm{S}_{2}=\mathrm{S}_{1}+$ thin layer of printed UV varnish;

- $\mathrm{S}_{2 \mathrm{~B}}=\mathrm{S}_{2}$ + braille dots printed with maximum five layers of $U V$ varnish $\left(S_{2 B 1}\right.$ - with one layer, $S_{2 B 2}$ - with two layers etc.);

- $S_{2 B S E}=S_{2 B 5}$ + element printed on the braille dot with maximum five layers of $U V$ varnish $\left(S_{2 B 5 E 1}\right.$ - with one layer, $\mathrm{S}_{2 \mathrm{BSE2} 2}$ - with two layers etc.)

\section{Methods}

In the analysis of the samples the following properties were determined: grammage (International Standardization Organization, 1995), height of the printing substrate and the prints, which was measured on the apparatus for measuring thickness (Metrimpex, Hungary) (International Standardization Organization, 1988); specific volume of the material, which was calculated from the grammage and thickness; roughness, which was measured on the Bentsten 3500 (Zehntner GmbH, Swiss) (International Standardization Organization, 1990); absorption, which was measured by the drop test (the results are presented as the time $[\mathrm{s}]$ required for the drop to be absorbed into the sample; if the time was higher than $600 \mathrm{~s}$, the sample was considered to be nonabsorbing) (TAPPI 432); bending stiffness, which was measured on the dynamometer INSTRON mod. 5567 (Instron Ltd., USA) and recorded as a force needed to bend sample for $15^{\circ}$ and bending length $50 \mathrm{~mm}$ (International Standardization Organization, 2011); capillary rise (International Standardization Organization, 1986) and contact angle, which was measured on the Optical Tensiometer OneAttension Theta (Biolin Scientific Holding AB, Finland) (American Society of the International Association for Testing and Materials, 2013).

An image analyses of the samples (cross sections, surface specifics of the cardboard, braille dots and added elements) were performed by scanning electron microscopy (SEM; JSM 6060 LV, Jeol, Japan). For the observation with SEM, the samples were covered with an ultrathin coating of gold (with high vacuum evaporation).

On the selected prints sensory analysis was performed. On all the samples the same text (a short sentence, with capital and small letters together with some numbers) was printed. Due to the fact that there was a large amount of the samples, only $\mathrm{S}_{2 B}$ and $\mathrm{S}_{2 B 5 E}$ prints made with one, three and five layers, were tested. Prints were tested by small groups of 12 blind and visually impaired people ( 7 males and 5 females) at the Slovenian Association of blind and visually impaired people. All the respondents have been learning braille for more than 5 years. $50 \%$ of the respondents considered themselves as very good readers and $25 \%$ as fairly good to basic readers, respectively. Each respondent was given the same selected samples and during the analysis was asked the questions about the height of the printed braille dots and the braille dots with the additional element, about the tactile recognition and the character identification, the recognition and the likeability of the printed additional element, as well as the sharpness of the final prints.

\section{Results and discussion}

\section{Properties of the substrates (samples $S_{1}$ and $S_{2}$ )}

The research started with the braille dot firstly printed on the sample $\mathrm{S}_{1}$ (unprinted cardboard). Since the UV varnish of the braille dot printed in one layer spread through the surface and slightly penetrated into the structure of the cardboard, the sample $S_{2}$ was introduced into the research. The sample $S_{2}$ represented the cardboard, on which surface a thin layer of the UV varnish (the same 
as was used for the braille dots) was printed. The properties and the comparison of the samples $\mathrm{S}_{1}$ and $\mathrm{S}_{2}$ are presented in Table 1 and described in continuation.

After a thin layer of the UV varnish was printed on the cardboard $\left(\mathrm{S}_{2}\right)$, the grammage and the thickness of the unprinted cardboard $\left(S_{1}\right)$ increased. Consequently, the specific volume slightly decreased. The thickness of the UV layer printed on the surface of $\mathrm{S}_{2}$ sample was $0.024 \mathrm{~mm}$. The upper and back surfaces of the $\mathrm{S}_{1}$ sample were rougher than the surfaces of $\mathrm{S}_{2}$.

\section{Table 1}

Properties of the unprinted cardboard $\left(\mathrm{S}_{1}\right)$ and the cardboard printed with a thin layer of UV varnish $\left(S_{2}\right)$ (values in the brackets represent the coefficient of variation [\%])

\begin{tabular}{l|c|c}
\hline \multicolumn{1}{|c|}{ Sample } & $\mathrm{S}_{1}$ & $\mathrm{~S}_{2}$ \\
\hline Property & $242.60(0.24)$ & $268.20(0.35)$ \\
\hline Grammage $\left[\mathrm{g} / \mathrm{m}^{2}\right]$ & $0.407(0.77)$ & $0.431(0.62)$ \\
\hline Thickness $[\mathrm{mm}]$ & - & 0.024 \\
\hline $\begin{array}{l}\text { Thickness of the } \\
\text { printed layer }[\mathrm{mm}]\end{array}$ & 1.678 & 1.607 \\
\hline Spec. volume $\left[\mathrm{cm}^{3} / \mathrm{g}\right]$ & $197.13(10.04)$ & $216.74(10.88)$ \\
\hline $\begin{array}{l}\text { Bending stiffness }[\mathrm{mN}] \\
\text { MD }\end{array}$ & $376.38(4.96)$ & $356.59(7.71)$ \\
CD & $436.67(20.05)$ & $49.33(28.37)$ \\
\hline $\begin{array}{l}\text { Roughness }[\mathrm{ml} / \mathrm{mm}] \\
\text { Side A }\end{array}$ & $883.33(8.19)$ & $840.00(16.56)$ \\
Side B & $53.20(1.57)$ & $57.80(0.77)$ \\
\hline $\begin{array}{l}\text { Capillary rise }[\mathrm{mm}] \\
\text { MD } \\
\text { CD }\end{array}$ & $58.40(4.12)$ & $59.00(2.08)$ \\
\hline Absorption $[\mathrm{s}]$ & $>600$ & $>600$ \\
Side A & 550 & 543 \\
Side B & 65.93 & 80.96 \\
\hline Contact angle $\left[^{\circ}\right]$ & & \\
\hline
\end{tabular}

On the Figure 2a can be seen, that the surface (upper A side) of $S_{1}$ was covered with the coating (also men-

a)

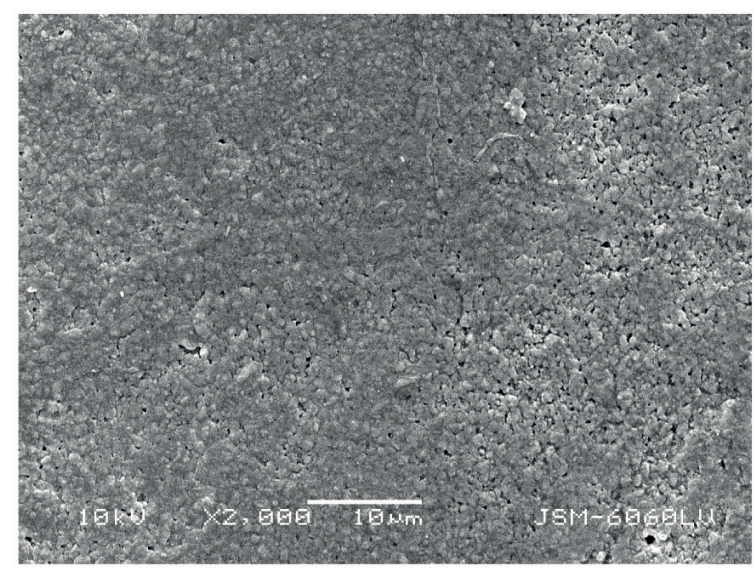

tioned by the manufacturer), which resulted in the granular surface with the pores smaller than $1 \mu \mathrm{m}$. The sample $\mathrm{S}_{2}$ had smoother surface on the side A (Figure $2 b)$, after it was printed with a thin layer of the UV varnish. The bending stiffness of the sample $S_{2}$ increased in the machine (MD) and just slightly decreased in the cross $(C D)$ direction according to the sample $\mathrm{S}_{1}$.

Measured values of the unprinted cardboard $\left(\mathrm{S}_{1}\right)$ capillary rise did not change significantly with printing of a thin layer of the UV varnish $\left(\mathrm{S}_{2}\right)$, neither in the machine (MD) and nor in the cross (CD) direction. According to the results of the drop test, the absorption of the water drop into the upper A side surface of the unprinted cardboard $\left(S_{1}\right)$ was very slow (higher than 600 s). Similar was observed for the sample printed with a thin layer of the UV varnish layer $\left(\mathrm{S}_{2}\right)$, which means that the upper A sides of both samples were completely nonadsorbing. However, the B side of both samples was slightly absorbent (<600 s). In comparison with the sample $\mathrm{S}_{1}$, the contact angle of the sample $\mathrm{S}_{2}$ increased, which means that a thin layer of printed UV varnish contributed to the reduction of the adhesiveness and the wettability as well as probably lowering of the surface free energy of the sample $S_{2}$. According to the properties of the samples $S_{1}$ and $S_{2}$, the braille dots were in continuation of the research printed only on the sample $S_{2}$ since less spreading of the UV varnish on the surface and less protruding into the substrate was expected.

\section{Properties of the samples $S_{2 B 1}-S_{2 B 5}$}

The braille dots were printed in different heights, achieved with different number of layers - from one $\left(S_{2 B 1}\right)$ to five $\left(S_{2 B 5}\right)$. The samples were observed by SEM (Figure 3) and the height of the samples was measured (Table 2). The height of the braille dots and individual layers was afterwards calculated form the measured values of individual samples.

b)

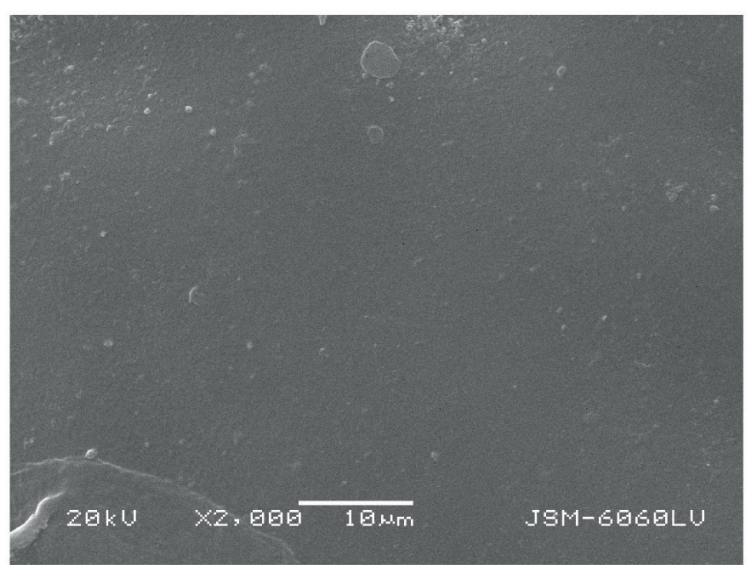

» Figure 2: Surface of the unprinted cardboard (S1) (a) and the unprinted cardboard printed with a thin layer of UV varnish (S2) (b) (SEM; 2000× mag.) 


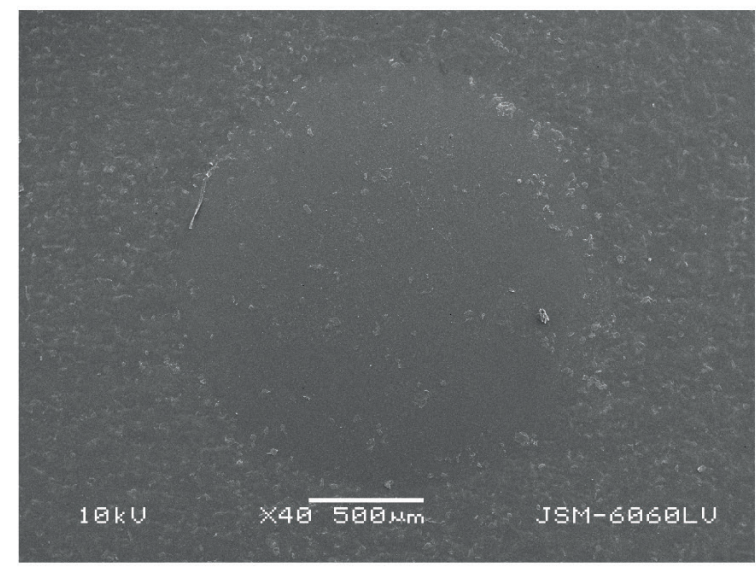

a2)

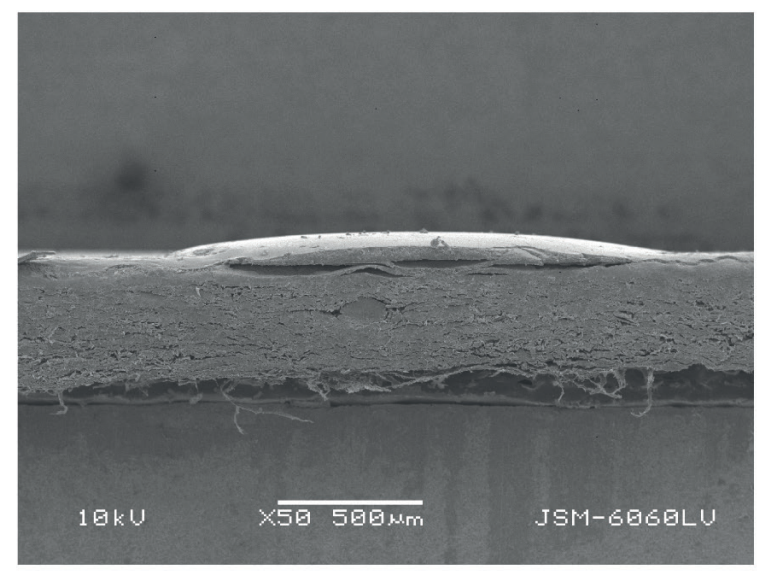

b1)

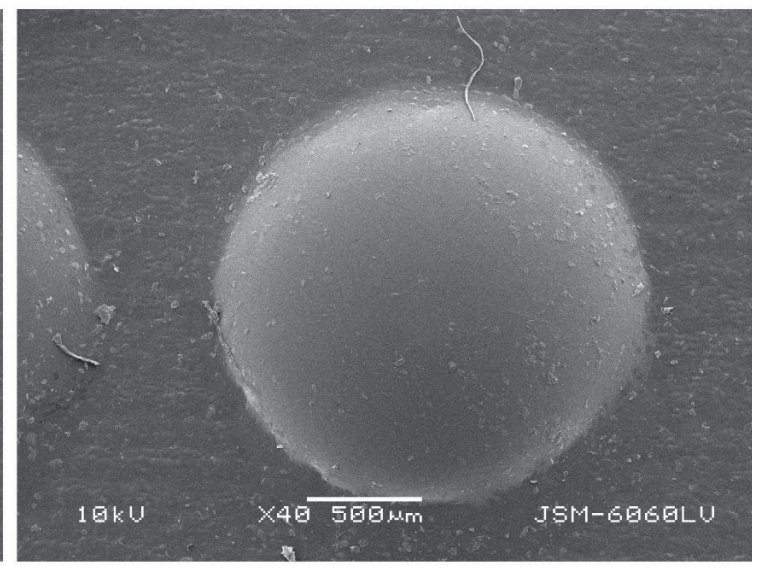

b2)

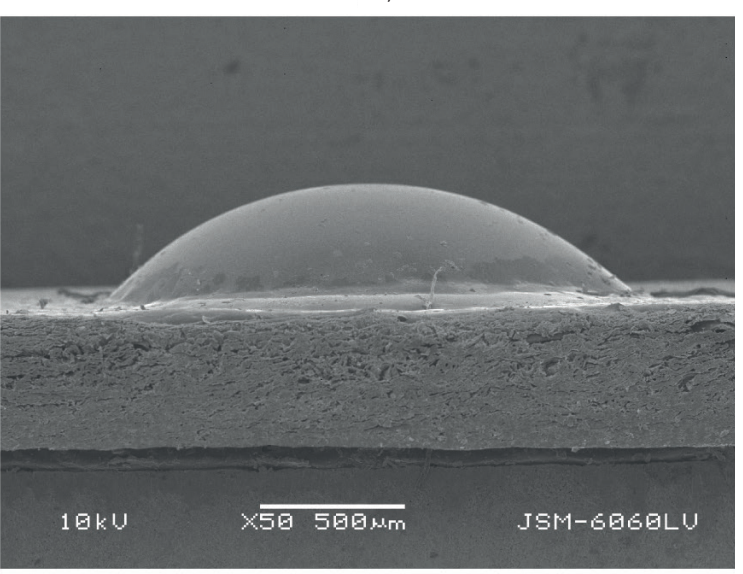

„ Figure 3: Surface and cross section of the braille dots printed with one $\left(S_{2 B 1}\right)$ (a1 and a2) and five layers $\left(S_{2 B 5}\right)(b 1$ and b2) on the sample $S_{2}$ (SEM; $40 \times$ and 50x mag.)

On the Figure 3 the braille dots printed with one (a1 and $\mathrm{a} 2$ ) and five (b1 and b2) layers on the sample $\mathrm{S}_{2 \mathrm{~B}}$ are shown. The diameter of the printed braille dots (Figure 3b1) was $1.83 \mathrm{~mm}$, by which the prescribed requirements were met. As can be seen from the Figure $3 b 1$ the braille dot was uniform, although slight spreading of the UV varnish around the braille dot on the surface, which caused slightly blurred edges at the base of the braille dot, was noticed.
From the Table 2 it can be seen that the height of the samples $S_{2 B 1}-S_{2 B 5}$ increased almost linear with the calculated $R^{2}=0.999$. Consequently, the height of the braille dot increased linear with the each added layer of the UV varnish. The results have also shown that the prescribed requirements of the braille dot height, which needs to be at least $0.25 \mathrm{~mm}$, were obtained with the braille dots printed with four layers.

\section{Table 2}

Measured and calculated height of the samples $\mathrm{S}_{2 \mathrm{~B} 1}-\mathrm{S}_{2 \mathrm{~B} 5}$

\begin{tabular}{|c|c|c|c|c|c|c|c|}
\hline \multirow{2}{*}{ Sample } & \multirow{2}{*}{$\begin{array}{l}\text { Height of the } \\
\text { sample } \\
\text { [mm] }\end{array}$} & \multirow{2}{*}{$\begin{array}{l}\text { Height of the } \\
\text { braille dot } \\
\text { [mm] }\end{array}$} & \multicolumn{5}{|c|}{ Thickness of the individual layer [mm] } \\
\hline & & & 1 & $1+2$ & $1+2+3$ & $1+2+3+4$ & $1+2+3+4+5$ \\
\hline $\mathrm{S}_{2 \mathrm{~B} 1}$ & 0.468 & 0.037 & 0.037 & 0.037 & 0.037 & 0.037 & 0.037 \\
\hline $\mathrm{S}_{2 \mathrm{~B} 2}$ & 0.537 & 0.106 & & 0.070 & 0.070 & 0,070 & 0.070 \\
\hline $\mathrm{S}_{2 \mathrm{BB}}$ & 0.620 & 0.189 & & & 0.083 & 0.083 & 0.083 \\
\hline $\mathrm{S}_{2 \mathrm{~B} 4}$ & 0.700 & 0.269 & & & & 0.080 & 0.080 \\
\hline $\mathrm{S}_{2 B 5}$ & 0.784 & 0.353 & & & & & 0.084 \\
\hline
\end{tabular}


In the Table 2, an interesting phenomenon was observed with the thickness of the individual layers. Namely, the thickness of the first layer $\left(\mathrm{S}_{2 B 1}\right)$ was the lowest $(0.037$ $\mathrm{mm})$, significantly thicker was the second layer $\left(\mathrm{S}_{2 \mathrm{B2}}\right)$ $(0.070 \mathrm{~mm})$, however the third, fourth and fifth layers $\left(\mathrm{S}_{2 B 3}, \mathrm{~S}_{2 B 4}\right.$ and $\left.\mathrm{S}_{2 B 5}\right)$ were the thickest (in average 0.082 $\mathrm{mm}$ ). Connecting those results with the results of the SEM observation it could be concluded, that the first layer is the thinnest because of the spreading of the UV varnish used for printing braille dot at its base on the printing surface; protruding into the printed thin layer of
UV varnish, applied on the cardboard, or even into the printing sample's structure was excluded according to the results of the drop test. The following layers were significantly thicker, since spreading was (obviously) reduced.

Because the aim of our research was to produce distinguished prints, braille dots printed with five layers were selected as the base for printing additional elements. a1)

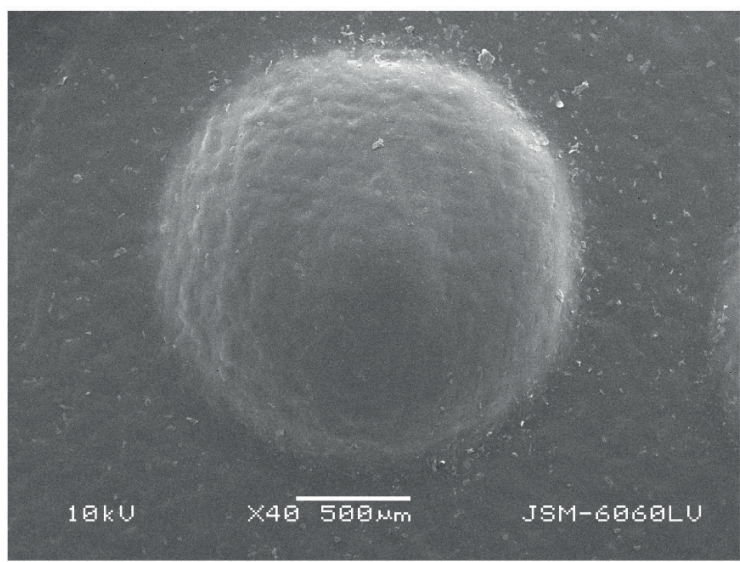

a2)

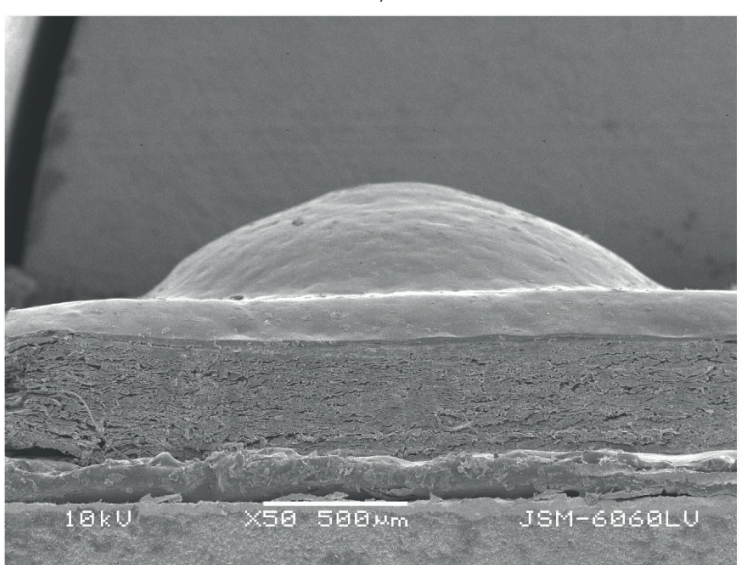

b1)

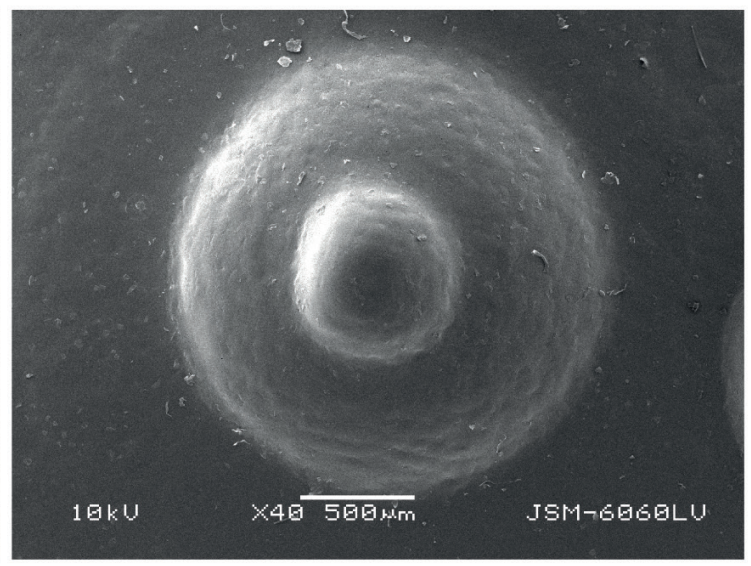

b2)

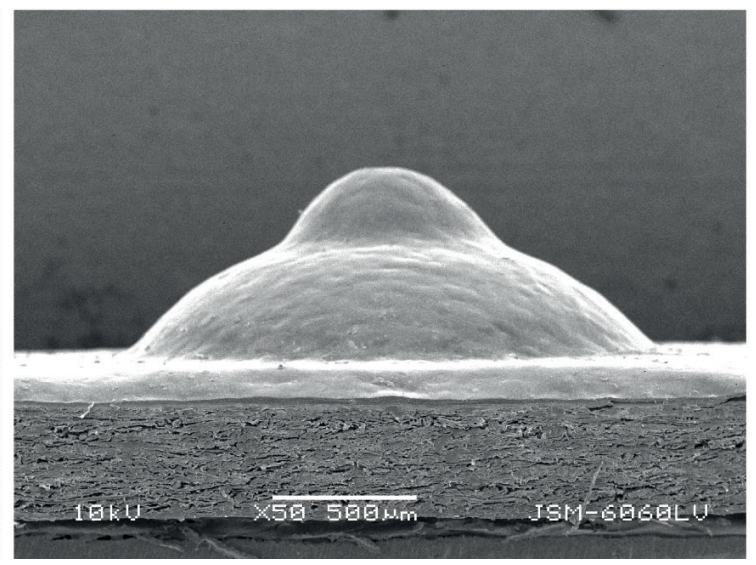

» Figure 4: Surface and cross section of the sample $S_{2 B 5}$ printed with the additional element with one $\left(S_{2 B 5 E 1}\right)$ (a1 and a2) and five layers $\left(S_{2 B 5 E 5}\right)$ (b1 and b2) (SEM; $40 \times$ and $50 \times$ mag.)

\section{Table 3}

Measured and calculated height of the samples $\mathrm{S}_{2 B 5 E 1}-\mathrm{S}_{2 B 5 E 5}$

\begin{tabular}{c|c|c|c|c|c|c|c}
\hline \multirow{2}{*}{ Sample } & \multirow{2}{*}{$\begin{array}{c}\text { Height of the } \\
\text { sample } \\
{[\mathrm{mm}]}\end{array}$} & $\begin{array}{c}\text { Height of the } \\
\text { braille dot } \\
{[\mathrm{mm}]}\end{array}$ & \multicolumn{5}{|c}{ Thickness of the individual layer [mm] } \\
\cline { 5 - 8 } & & & 1 & $1+2$ & $1+2+3$ & $1+2+3+4$ & $1+2+3+4+5$ \\
\hline$S_{2 B 5 E 1}$ & 0.809 & 0.025 & 0.025 & 0.025 & 0.025 & 0.025 & 0.025 \\
\hline$S_{285 E 2}$ & 0.844 & 0.060 & & 0.035 & 0.035 & 0.035 & 0.035 \\
\hline$S_{285 E 3}$ & 0.888 & 0.104 & & & 0.044 & 0.044 & 0.044 \\
\hline$S_{285 E 4}$ & 0.937 & 0.153 & & & & 0.049 & 0.049 \\
\hline$S_{285 E 5}$ & 1.060 & 0.276 & & & & & 0.123 \\
\hline
\end{tabular}


a)

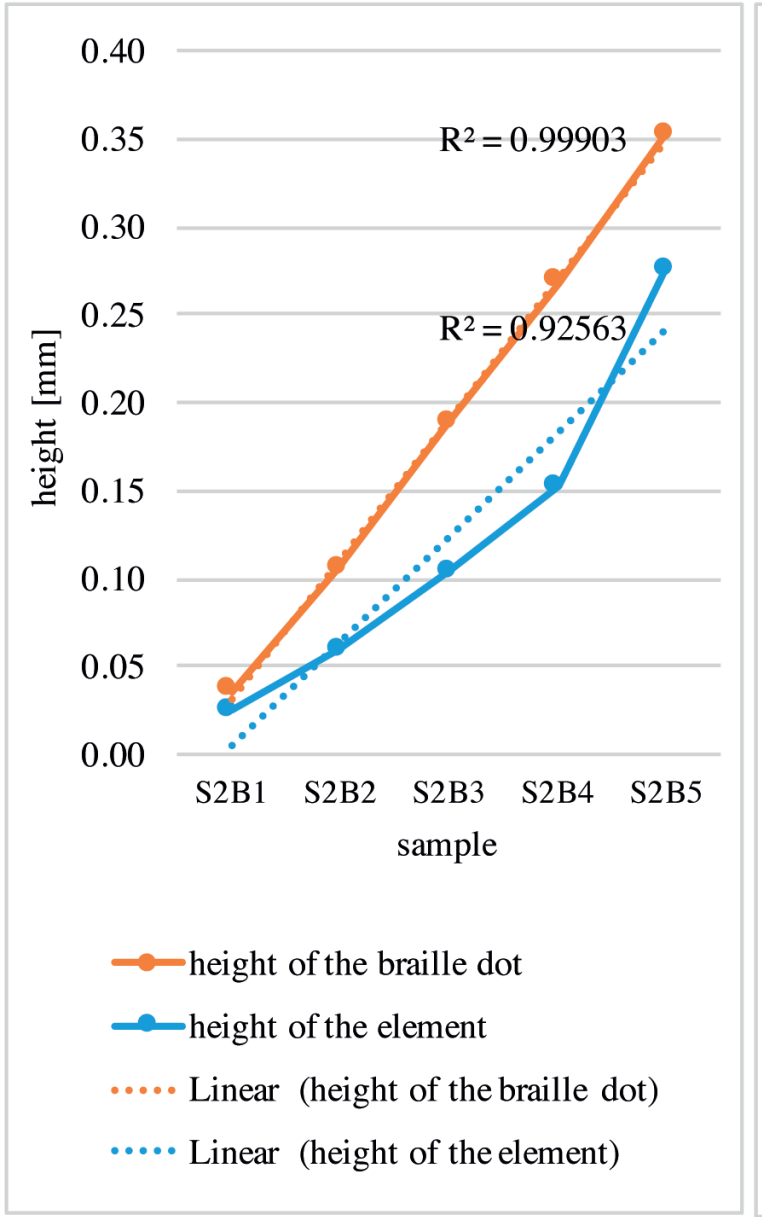

b)

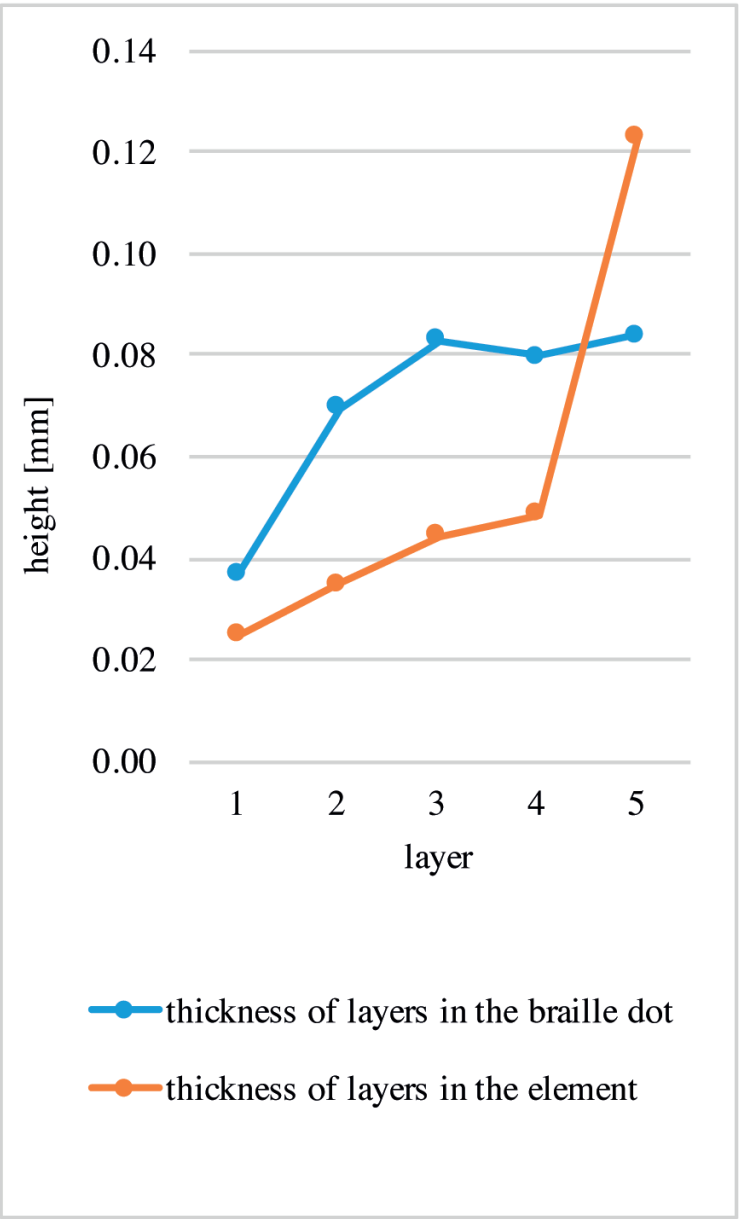

» Figure 5: The height (a) and the thickness (b) of the braille dots and the additional elements

\section{Properties of the samples $S_{2 B 5 E 1}-S_{2 B 5 E 5}$}

After the printing substrate $\left(\mathrm{S}_{2}\right)$ and the height of dot $\left(\mathrm{S}_{2 B 5}\right)$ were chosen, the additional elements were printed on the braille dots with one to five layers and tested by the blind and visually impaired people. Obtained results are presented on the Figure 4 and in the Table 3.

As it can be seen from the Figure 4, the additional element printed with only one layer ( $a 1$ and b1) was almost unrecognizable, while five layered element (a2 and b2) was clearly seen. Same as in the case of the printed braille dots $\left(S_{2 B 1}-S_{2 B S}\right)$, the printed elements had slightly blurred edges at the base, which could be due to the slight spreading of the UV varnish around the first layer of the printed element.

In the Table 3 can be seen that the printed layers of additional elements had very similar thickness (except for the fifth layer, which thickness increased incomprehensibly). The first layer again (as in the case of sample $\mathrm{S}_{2 \mathrm{~B} 1}$ ) had the lowest thickness, probably due to the slight spreading of the UV varnish.
The he ight of all prints made with the additional elements meet the requirements of braille dot height.

Comparing the height values of the braille dots and the additional elements (Figure $5 a$ a) it could be seen that additional elements had lower height, which increased slowly, however the height of braille dots increased more rapidly. In both cases the increase is linear (for the braille dot $R^{2}=0.999$ and for the additional elements $R^{2}$ $=0.9258$ ). In the Figure $5 b$ the thickness of the individual layer of the braille dots and the additional elements are presented. The layers in the additional elements were thinner while thickness increased more slowly and mostly linear (except for the last unusual increase); the first layer in the braille dot was thinner (due to the spreading of varnish), however the others layers had almost the same thickness without the increase.

\section{Sensory analysis}

According to the results of the sensory analysis all respondents liked the smooth surface of coated cardboard substrate and the tactile effect of printed braille dots, though some commented that its surface was a bit 


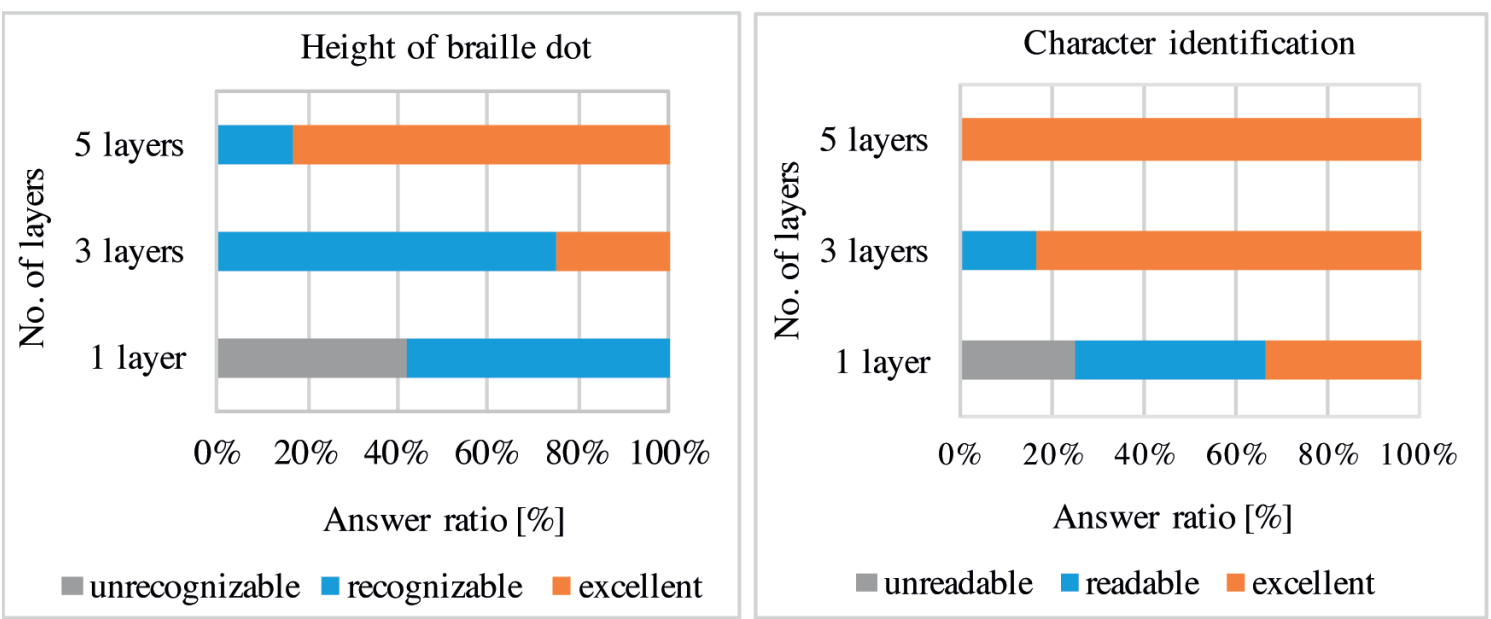

» Figure 6: Recognition of the height (a) and the character recognition (b) of the braille dots

harder, compared to classical embossed braille. From the Figure 6 can be seen that the respondents evaluated the height of the samples printed with only one layer of the braille dot as unrecognizable to poorly recognizable. The detection of height increased with the number of the layers and more than $80 \%$ of respondents evaluated braille dots printed with five layers as excellent (Figure $6 a)$. The result were supported with the character identification where even samples printed with three layers were graded as suitable (Figure 6b). Consistent with the sensory analysis results of the height of the braille dots printed without the additional elements (where all the respondents evaluated the printed braille dot height as recognizable and excellent), only $8.33 \%$ of the respondents graded the braille dots with printed one layer of additional layer as unrecognizable. All other graded the height of the braille dots printed with one layer of additional element as recognizable and even a bit over $40 \%$ of the respondents as excellent Figure 7). Due to the fact that the additional elements were printed on the top of five layered basis braille dots it is no surprise that the height was graded in almost all layers as recognizable.

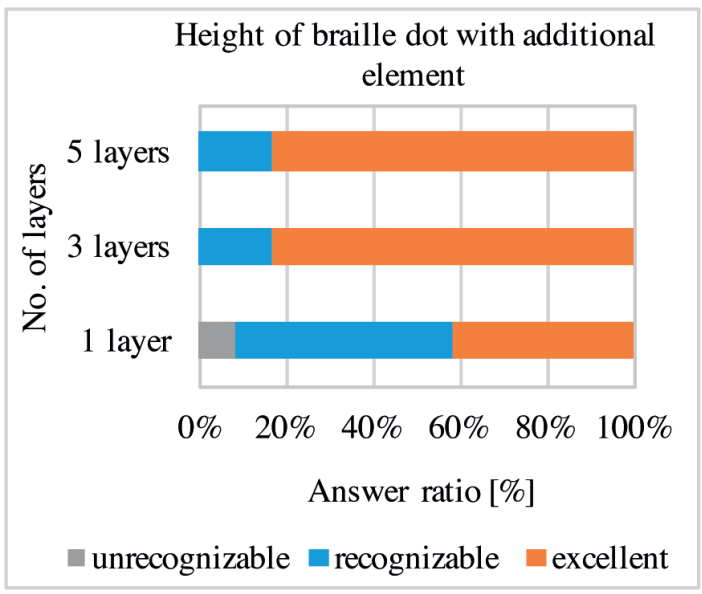

» Figure 7: Recognition of the braille dot height printed with the additional element with one to five layers
From the results in Figure 8a can be seen that the shape of the additional elements was not recognized when printed in one layer but the recognition increased with the increase of printed layers and thus with its height. Only $25 \%$ of the respondents did not detect the shape of the additional elements printed with five layers. Due to the fact that the additional elements were insufficiently recognized when printed in one layer, the results of poor recognition even in five layers was expected. We could conclude that upon results of the sensory analyses additional elements were liked in about half of the respondents, though no one could recognize its shape (Figure $8 b$ ). The likeability of the additional element decreased with the number of printed layers. Consequently the additional elements printed in thinner layers were graded as suitable, while five layered were evaluated by the respondents as too sharp and unpleasant to touch Figure 8c.

\section{Conclusions}

UV ink-jet printing enables production of braille dots, which meet the prescribed standard values of all braille dot parameters - the height, the diameter, the cell dimensions etc. In this research it was shown, that the braille dots could be qualitatively printed directly onto the surface of the selected substrate if this was printed with a thin layer of varnish, so that the shape of the braille dots stayed uniform.

As expected when printing in different layers, the height and the thickness of the printed samples increased. Not all layered samples were suitable; for the achievement of sufficient standard braille dot height at least four or even better five layers of UV varnish needed to be printed so that blind and visually impaired people could recognize the written notation. Research has shown that the braille dot printed with only one layer of UV varnish $\left(\mathrm{S}_{2 B 1}\right)$ had the lowest height due to 


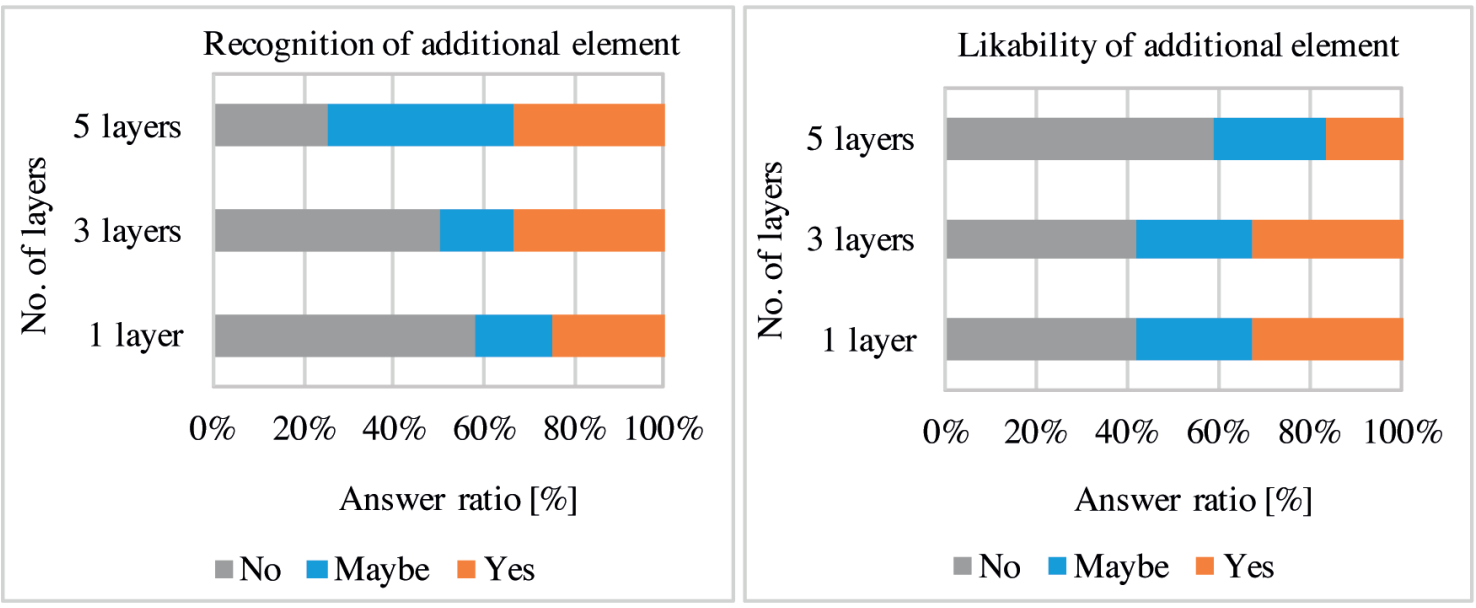

c)

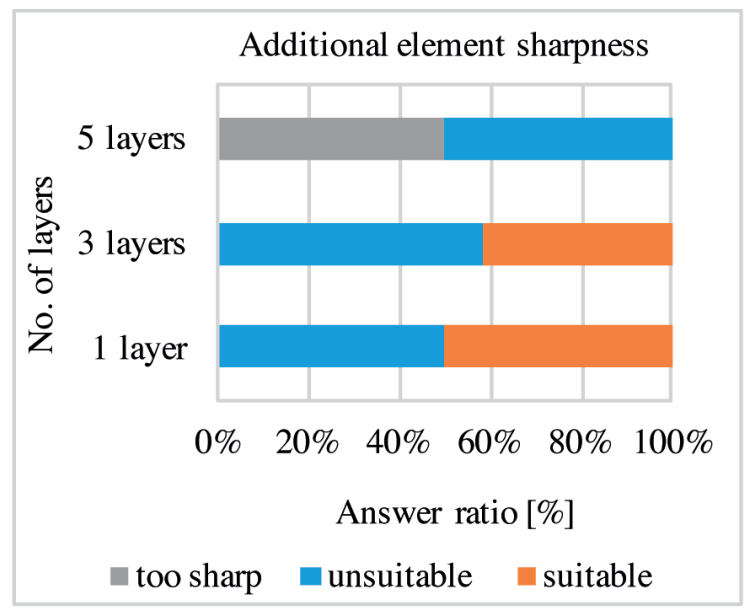

» Figure 8: Recognition (a), likability (b) and sharpness (c) of the additional elements printed in different layers

the spreading of the UV varnish on the surface of the printing substrate and not its adsorption, which was proven with the drop test and contact angle results. the following layers had almost the same thickness.

Analyses of the samples with printed additional elements on appropriately high braille dots have shown that the similar effect can be observed height of the one layered additional element was the lowest while others stayed almost the same. The increase was linear with small deviations.

Sensory analysis has confirmed the results of determined properties of all printed samples. The recognition of the printed braille dotes increased with the number of printed layers, while with printed additional elements lower number of layers did not contribute to their recognition. Blind and visually impaired respondents distinguished the tactile surface of the braille dot samples and the samples printed with the additional elements but only as "different to touch", they were not able to recognize the printed shape of the additional element. Nevertheless, research has shown that the tactile surface differs to the extent that the use of the braille dots with printed additional elements could be used for distinguishing the written notations.

Though this study offers a new inside into the field of braille writing we believe that with a reasonable determination of separate characters, signs, letters etc. progress in simplified braille can be made.

\section{References}

American Association of Workers for the Blind, Association for Education of the Visually Handicapped and the National Braille Association (AAWBAEVH-NBA). (1987) The Nemeth Braille code for mathematics and science notation 1972 revision. Louisville, American Printing House For The Blind. Available from: https://www.prcvi.org/files/ braille/Nemeth-Code-Mathematics-Science-Notation-1972-Revision. pdf [Accessed 29th June 2017].

American Society of the International Association for Testing and Materials. (2013) ASTM D7334-08. Standard Practice for Surface Wettability of Coatings, Substrates and Pigments by Advancing Contact Angle Measure- 
ment. West Conshohocken, American Society of the International Association for Testing and Materials.

Braille Authority of North America (BANA).

(1997) Music Braille code. Louisville, American Printing House for the Blind.

Chang, Y. (2012) Braille ink-jet printing apparatus and printing method thereof. WO 2012163212 A1 (Patent).

Deutsches Institut für Normung e.V. (2007) DIN 32976. Braille - requirements and dimensions. Berlin, Deutsches Institut für Normung e.V.

Deutsches Institut für Normung e.V. (2009) DIN 55561:2009-01. Packaging - Braille on packaging. Berlin, Deutsches Institut für Normung e.V.

European Commission: Enterprise and Industry Directorate- General. (2001) Directive 2001/83/EC Article $56 a$-Guidance concerning the Braille requirements for labeling and the package leaflet. Available from: http://academy.gmp-compliance.org/guidemgr/files/ BRAILLE_TEXT20050411.PDF [Accessed 10th July 2017].

European Committee for Standardization. (2008) PD CEN/TR 15753. Packaging - Package Leaflets For Medicinal Products - Braille And Other Formats For Visually Impaired People. Brussels, European Committee for Standardization.

Fajdetić, A. (2012) Standardisation of Braille in the EU and other European Countries. In: Schwan, J. \& Kahlisch,

T. (eds.) Proceedings of World Congress Braille21 Innovations in Braille in the 21st Century, 27-30 September 2011, Leipzig, Germany. Leipzig, German Central Library for the Blind in Leipzig. pp. 287-294.

Hee, H. I. (2015) Braille music for Korea classical music and method for notation. KR 20150030437 (Patent).

International Standardization Organization. (2014) ISO 15823:2014. Packaging - Braille on packaging for medicinal products. Geneva, International Standardization Organization.

International Standardization Organization. (2013a) ISO 17351:2013. Braille on packaging of medicines. Geneva, International Organization for Standardization.

International Standardization Organization. (2013b) ISO 17351:2013. Packaging - Braille on packaging for medicinal products. Geneva, International Standardization Organization.

International Standardization Organization. (1995) ISO 536:1995. Paper and board - Determination of grammage. Geneva, International Standardization Organization.

International Standardization Organization. (1988) ISO 534:1990. Paper and board - Determina- tion of thickness and apparent bulk density or apparent sheet density. Geneva, International Standardization Organization.

International Standardization Organization. (1990) ISO 8791-2:1990. Paper and board - Determination of roughness/smoothness (air leak methods) - Part 2: Bendtsen method. Geneva, International Standardization Organization. International Standardization Organization. (2011) ISO 2493-2:2011. Paper and board - Determination of resistance to bending. Geneva, International Standardization Organization.

International Standardization Organization. (1986) ISO 8787:1986. Paper and board-Determination of capillary rise - Klemm method. Geneva, International Standardization Organization.

Količevo Karton d.o.o. (2005) Quality report.

La Commission Évolution du Braille Français. (2007) Notation Mathematique Braille. Paris, Le Département de Transcription et d'Édition Adaptée, Institut National des Jeunes Aveugles. Available from: https:// www.avh.asso.fr/sites/default/files/notation_mathematique_braille2_0.pdf [Accessed 29th June 2017].

Österreichisches Normungsinstitut für Normung e.V. (2006) ÖNORM V 2105:2006 06 01. Technical aids for visually impaired and blind persons - tactile inscriptions and information systems. Vienna, Osterreichisches Normungsinstitut für Normung e.V.

Reynaud, G. (1995) Braille printing process using conventional printing techniques. FR 2717420 (A1) (Patent).

Wensco. (2016) Roland ECO - UV Gloss printing ink: UV Gloss Clear Ink Cartridge 220cc. Available from: https://www.wensco.com/itemdetail/EUVGL. [Accessed 24th July 2016].

Shi-Chang, Z. \& Rui-Zhang, J. (2013) Composite reading products allowing both sighted and visually impaired people to use. TW 201323248 (A) (Patent).

Soleimani-Gorgani, A. (2016) Inkjet printing. In: Izdebska, J. \& Thomas, S. (eds.) Printing on Polymers: Fundamentals and Application. Amsterdam, Elsevier. pp. 231-247.

Roland. (2016) Versa UV LEC330. Available from: http:// www.rolanddg.com/en/products/lineup/versauv-lecseries-uv-led-print-and-cut [Accessed 24th July 2016].

Zhang, Y. (2011) Inkjet printing device for Braille. CN 202071517 (U) (Patent).

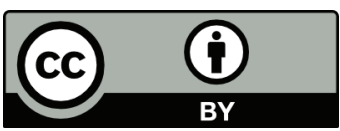

(C) 2016 Authors. Published by the University of Novi Sad, Faculty of Technical Sciences, Department of Graphic Engineering and Design. This article is an open access article distributed under the terms and conditions of the Creative Commons Attribution license 3.0 Serbia (http://creativecommons.org/licenses/by/3.0/rs/). 